\title{
Questionnaire-Based Survey on Management of Ulcerative Colitis-Associated Cancer in East Asian Countries
}

\author{
Satoru Yamaguchi ${ }^{a}$ Kinro Sasaki $^{a}$ Hiroyuki Kato $^{a}$ Shin Fukudo ${ }^{b}$

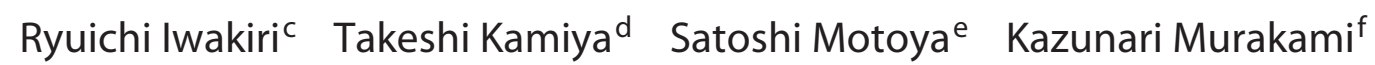 \\ Akihito Nagaharag ${ }^{9}$ Hidekazu Suzuki $^{\text {h }}$ Toshio Watanabe ${ }^{i}$ Shin'ichi Takahashi ${ }^{j}$ \\ Francis K.L. Chan $^{k}$ Ki-Baik Hahm' Udom Kachintorn ${ }^{m}$ Fock Kwong Ming ${ }^{\text {n }}$
}

Abdul Aziz Rani ${ }^{\circ}$ Jose D. Sollano ${ }^{p}$ Qi Zhu ${ }^{q}$

${ }^{a}$ Department of Surgery I, Dokkyo Medical University, Tochigi, Japan; b Tohoku University Graduate School of Medicine, Miyagi, Japan; ' Choseikai Kinosita Clinic, Saga, Japan; dDepartment of Medical Innovation, Nagoya City University Graduate School of Medical Sciences, Aichi, Japan; 'Sapporo Kosei General Hospital, Hokkaido, Japan;

${ }^{f}$ Department of Gastroenterology, Oita University, Oita, Japan; 9 Department of Gastroenterology, Juntendo University School of Medicine, Tokyo, Japan; ${ }^{\text {h}}$ Fellowship Training Center and Medical Education Center, Keio University School of Medicine, Tokyo, Japan; 'Osaka City University Graduate School of Medicine, Osaka, Japan; jKosei Hospital, Tokyo, Japan; ${ }^{\text {k}}$ Faculty of Medicine, The Chinese University of Hong Kong, Hong Kong, China; 'Digestive Disease Center, CHA University School of Medicine and CHA University Bundang Medical Center, Seoul,

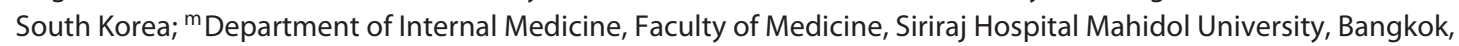
Thailand; " Department of Gastroenterology, Changi General Hospital, Singapore, Singapore; ${ }^{\circ}$ Department of Internal Medicine, Faculty of Medicine, University of Indonesia Cipto Mangunkusumo Hospital, Jakarta, Indonesia; PUniversity of Santo Tomas, Manila, Philippines; ${ }^{9}$ Sino United Health Clinic, Gopher Medical Center, Rui Jing Hospital, Shanghai Jiao Tong University School of Medicine, Shanghai, China

\section{Keywords}

Ulcerative colitis · Colitis-associated cancer · Dysplasia ·

Diagnosis $\cdot$ Endoscopic treatment $\cdot$ Surgical treatment

\begin{abstract}
Background/Aims: To elucidate the current management of ulcerative colitis (UC)-associated cancer, a questionnairebased survey was conducted to gather current opinions on colitis-associated cancer in different East Asian countries. Methods: The questionnaire, based on physicians, contains 9 questions focused on UC management and cancer surveil-
\end{abstract}

\section{KARGER}

๑ 2018 S. Karger AG, Basel

E-Mail karger@karger.com

www.karger.com/dig lance. In addition, the questionnaire based on neoplastic cases, which contains 17 questions, was collected and analyzed. Results: With regard to the diagnosis of UC-associated cancer, most respondents started surveillance colonoscopy within 10 years from onset, favored targeted biopsies, and thought advanced imaging was useful. As for morphology, the frequency of elevated lesion and type 4 lesions was most common in early and advanced cancer, respectively. Peritoneal metastasis was frequently observed, and undifferentiated tumor was frequently developed. Laparoscopic surgery was widely used because it is less invasive. The prognostic outcome was poor, particularly in stage III and undifferenti- 
ated type. Conclusions: The current survey elucidated the current management in Asian countries and characteristics of colitis-associated cancer in these countries.

(c) 2018 S. Karger AG, Basel

\section{Introduction}

The prevalence and incidence of ulcerative colitis (UC) are lower in East Asia than in Western countries. However, marked increases have been recently reported. Although the prognosis of UC is generally good, the mortality rate increases once colon cancer has developed. Several reports described that the estimated risk of UC-associated cancer at 10,20 , and 30 years is $0.5-2 \%, 1.1-8 \%$, and $18 \%$, respectively [1-3]. Overall, the incidence of UC-associated colorectal cancer (CRC) has been increased in those areas [4]. Colitis-associated CRC does not present the adenoma-carcinoma sequence, which is typical of sporadic CRC, and the clinicopathological characteristics were different compared to sporadic CRC [5]. To elucidate the current management of UC-associated cancer, a questionnaire-based survey was conducted to gather current opinions on colitis-associated cancer in different East Asian countries.

\section{Subjects and Methods}

\section{Participants}

A questionnaire was provided by representative International Gastrointestinal Consensus Symposium committee members to selected physicians in each country, starting in July 2017. Responses were collected by electronic mail until the end of November 2017. The questionnaire contains 9 questions focused on UC management and cancer surveillance. In addition, the questionnaire based on neoplastic cases, which contains 17 questions, was collected and analyzed. The questionnaire is attached in the Appendix.

\section{Statistical Analysis}

Continuous variables were expressed as mean or median, as appropriate. Categorical variables were presented as number and percentage. The prognostic comparison between groups was performed using the log-rank test. All statistical analyses were performed using the R statistical software.

\section{Results}

\section{Physician's Survey}

The respondents are from China, Hong Kong, Indonesia, Japan, South Korea, Philippines, Singapore, and Thailand. Table 1 shows the number of respondents
Table 1. Number of physicians who participated in this questionnaire-based survey

\begin{tabular}{lcccc}
\hline Country & Number & $\begin{array}{l}\text { Specialist } \\
\text { on IBD }\end{array}$ & $\begin{array}{l}\text { Non-specialist } \\
\text { on IBD }\end{array}$ & ND \\
\hline China & 21 & 15 & 6 & 0 \\
Hong Kong & 20 & 7 & 13 & 0 \\
Indonesia & 29 & 19 & 9 & 1 \\
Korea & 24 & 23 & 1 & 0 \\
Japan & 106 & 67 & 38 & 1 \\
Philippines & 29 & 1 & 27 & 1 \\
Singapore & 1 & 1 & 0 & 0 \\
Thailand & 20 & 3 & 17 & 0 \\
\hline Total & 250 & 136 & 111 & 3 \\
\hline
\end{tabular}

IBD, inflammatory bowel disease; ND, not determined.

from each country and their specialty in inflammatory bowel disease (IBD). The total number of respondents is 250 physicians. Most of the respondents belonged to a university, hospital, or clinic. A total of 106 respondents were from Japan, approximately 30 respondents from Indonesia and Philippines, and approximately 20 respondents from China, Hong Kong, Korea, and Thailand. With regard to their specialty, the ratio of specialist is relatively high in China, Indonesia, Korea, and Japan.

Figure 1 shows the number of patients with UC in the respondent's institution. The boxplot presented the number of patients with UC. In China, Japan, and Korea, one institution manages 200-300 patients. Approximately, 80 and 20 patients were treated per institution in Hong Kong and Indonesia, and the Philippines and Thailand, respectively.

Surveillance colonoscopy is necessary to detect neoplasia in patients with UC. Figure 2 shows the timing for the initiation of surveillance colonoscopy. The boxplot shows years from onset. The median ranged from 5 to 10 years from onset. Figure 3 shows the methods of biopsy. The ratio differs in each country. The ratio of random biopsy was relatively high in the Philippines and Thailand. However, approximately $70 \%$ of respondents favored targeted biopsies. Subsequently, the item regarding the number of cases detected in the last 5 years was included. Each respondent detected few colitis-associated cancers per year as shown in Figure 4. The usefulness of advanced imaging colonoscopy is shown in Figure 5. Approximately, $80 \%$ of respondents thought that advanced imaging was useful in detecting neoplasia compared with white light endoscopy. 
Fig. 1. Number of patients with UC in the respondent's institution is presented by the boxplot. The median is noted below the column.
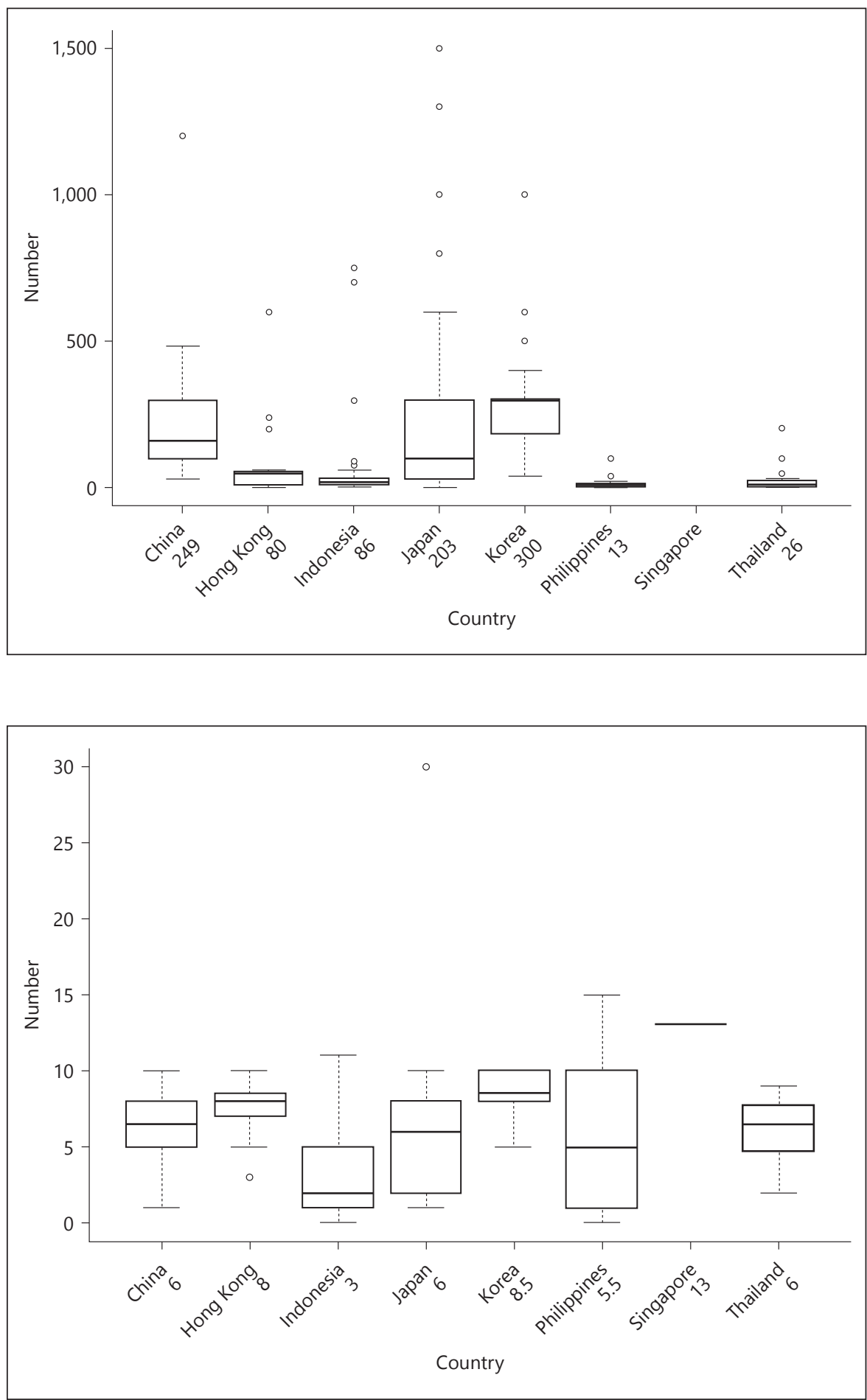

Fig. 2. Years from onset to starting surveillance colonoscopy in respondents are shown by the boxplot. The median is noted below the column. cancer reported from each country, with 95, 11, and 9 patients from Japan, China, and Korea, respectively. The mean age was approximately 55 years, suggesting that the patients with UC-associated cancer were younger than those with sporadic CRC, and 60 and $40 \%$ were men and wal number of UC-associated cancer cases was 125 . Table 2 shows the number of patients with UC-associated 
Fig. 3. Ratio for strategies of biopsy the respondent performs.

Fig. 4. Numbers of patients with UC-associated cancer respondent detected in the last 5 years. The mean value is noted below the column.
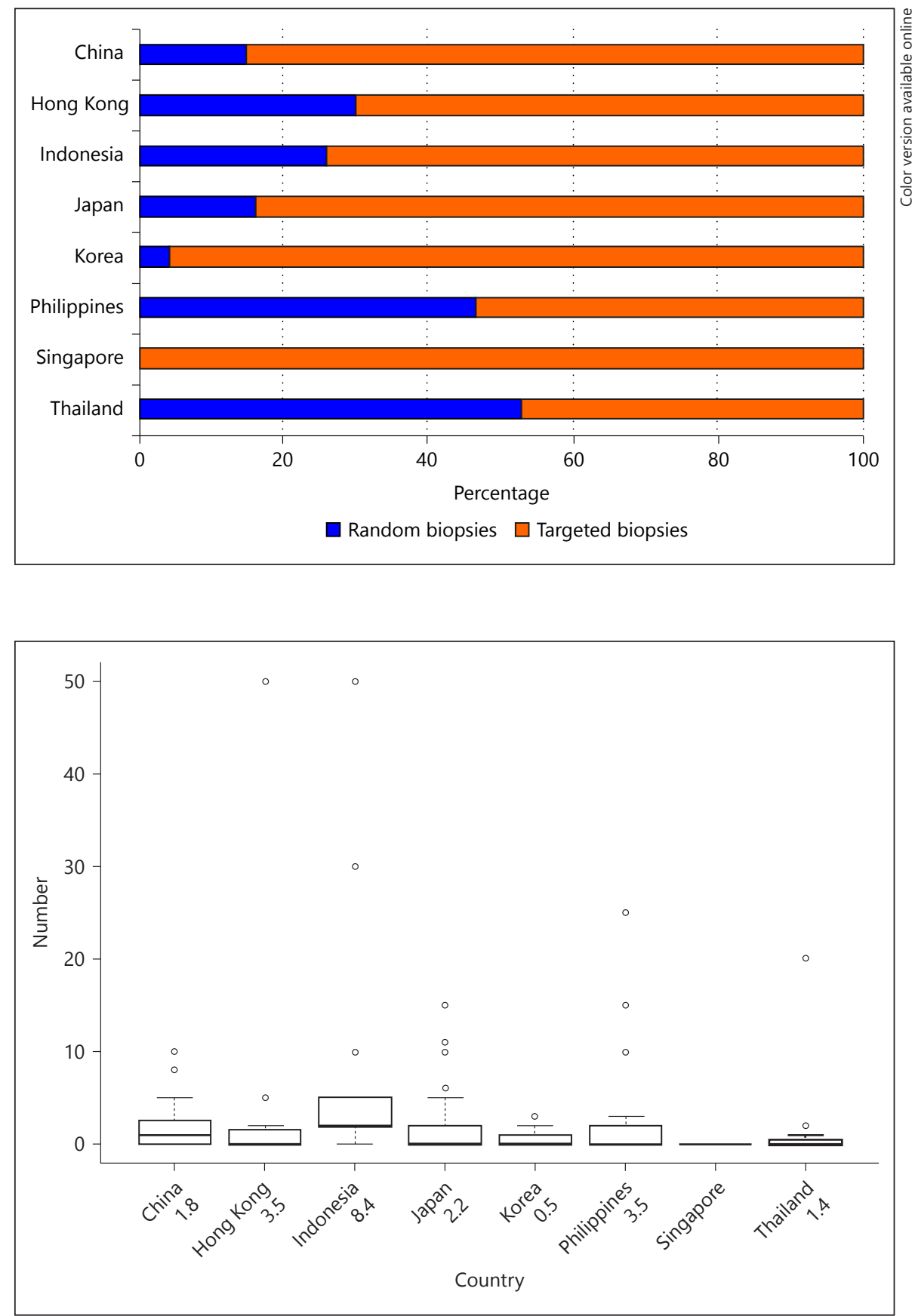

women, respectively. The mean from the onset was 10 20 years in each country.

For further study, we analyzed the entire population because the number of patients was biased in some countries. Table 3 shows the patient characteristics. The mean age was 52 years. With regard to the type of UC, the majority of them were total and left colitis types. Most patients were administered 5-aminosalicylic acid, with 50\% administered steroid, 25\% azathioprine, and 10\% anti-
TNF $\alpha$ antibody. Twenty-five lesions developed in the right colon, including the cecum, ascending colon, and transverse colon, whereas 108 lesions developed in the left colon, including the descending colon, sigmoid colon, and rectum. With regard to the macroscopic type, the ratio of the elevated type is high in early cancer. Type 2,3 , and 4 lesions are the dominant types in advanced cancer. The ratio of type 4 lesions seems to be higher than that of sporadic CRC. The mean tumor size was $39 \mathrm{~mm}$ 
Table 2. Number of neoplastic cases

\begin{tabular}{lclcc}
\hline Country & $\begin{array}{l}\text { Number } \\
\text { of cases }\end{array}$ & $\begin{array}{l}\text { Age, years, } \\
\text { mean (range) }\end{array}$ & $\begin{array}{l}\text { Gender, } \\
\text { male:female }\end{array}$ & $\begin{array}{l}\text { Years from onset } \\
\text { mean (range) }\end{array}$ \\
\hline China & 11 & $53.9(38-70)$ & $8: 3$ & $17.1(0-31)$ \\
Hong Kong & 3 & $57.7(41-68)$ & $3: 0$ & $19.7(15-23)$ \\
Indonesia & 5 & $53.4(48-64)$ & $5: 0$ & $11.2(3.5-25)$ \\
Japan & 95 & $52.0(7-87)$ & $53: 42$ & $17.6(1-59)$ \\
Korea & 9 & $47.3(30-78)$ & $6: 3$ & $16.4(4-35)$ \\
Philippines & 1 & NA & $0: 1$ & 15 \\
Thailand & 1 & 50 & $1: 0$ & \\
\hline Total & 125 & & & \\
\hline
\end{tabular}

Fig. 5. Ratio of advanced imaging the respondent thought to be effective.

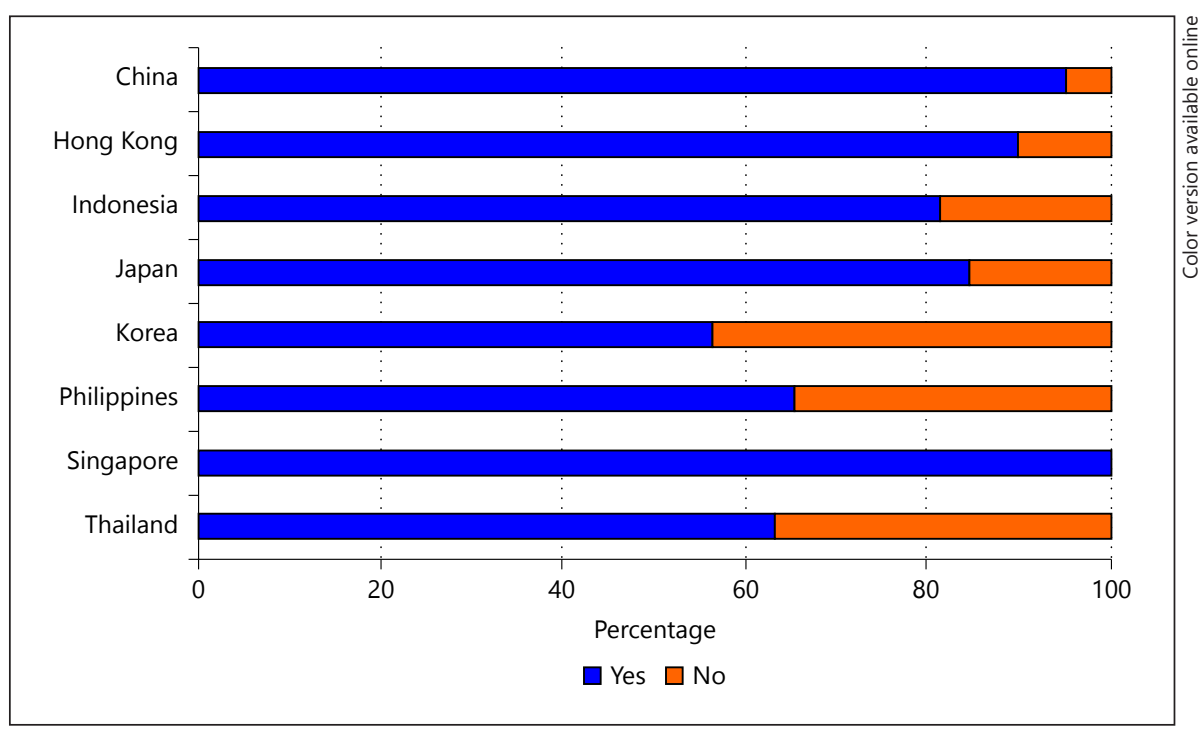

in diameter. With regard to the histology, 57 were tubular differentiated type, and approximately 10 were poorly or signet ring cell or mucinous carcinoma. The extent of cancer was also reported. Half of the available cases were advanced cancer, and 25 cases were lymph node metastasis, 2 cases were hepatic metastasis, 7 cases were peritoneal dissemination, and 3 cases were distant metastasis. The frequency of peritoneal dissemination seemed high.

Subsequently, we summarized the treatment for cancer. Nine patients were selected to undergo endoscopic treatment (Table 4), including endoscopic mucosal resection (EMR) and endoscopic submucosal dissection (ESD). Most of them were in situ carcinoma. Surgical treatment was selected in 79 cases. Chemotherapy was selected or added in 10 patients. Radiotherapy was selected, particularly for patients with advanced rectal cancer. In 79 patients who underwent surgery, laparoscopic surgery, total colectomy, and hand-sewn anastomosis were performed in 53,88 , and $52 \%$, respectively.

Subsequently, we performed survival analyses. With regard to stage, stage III has a worse prognosis than stages I and II cancer. The 5-year overall survival in stage III cancer seemed to be worse than that in sporadic CRC (Fig. 6a). No significant difference was observed between the left- and right-sided UC-associated cancer (Fig. 6b). Poorly, signet ring cell, and mucinous tumors were developed in $10 \%$ of all patients, and these tumors showed a significantly poorer prognosis than the differentiated type (Fig. 6c).

\section{Discussion}

In this study, a survey was conducted to determine the current management of colitis-associated cancer in East Asia. With regard to the diagnosis of UC-associated can-
90
Yamaguchi et al. 
cer, most respondents started surveillance colonoscopy within 10 years from onset, and favored targeted biopsies, and thought that advanced imaging was useful. With regard to the macroscopic findings, elevated lesion was most frequently observed in early cancer, and the frequency of type 4 lesions was high. Metastatic behavior, such as peritoneal metastasis, was frequently observed. Laparoscopic surgery was widely used because it is less invasive. The prognostic outcome was poor, particularly in those with stage III cancer. No significant difference was observed regarding the location of the tumor, and the undifferentiated type showed poorer prognosis than the differentiated type.

The morphology of colitis-associated cancer differs from sporadic CRC. Colitis-associated cancer often occurs as a widespread type. This feature makes identification of dysplastic lesions difficult when the tumor elevation and size is not large [6]. For this reason, advanced imaging was applied to colonoscopy surveillance. In this study, $70 \%$ of respondents favored advanced imaging. However, the clear benefit of narrow band imaging over conventional white light endoscopy or chromoendoscopy was not elucidated [7]. Recently, the SCENIC international consensus statement on surveillance and management of dysplasia in IBD was reported [8]. In the guideline, narrow-band imaging is not suggested as an alternative for white-light colonoscopy and chromoendoscopy to detect dysplasia. With regard to the surveillance method, target biopsy under pan-chromoendoscopy is preferentially recommended compared to random biopsy [9].

The behavior of colitis-associated cancer differs from that of sporadic CRC. Colitis-associated cancer often occurs multifocally. Therefore, performing total proctocolectomy is recommended if any dysplastic or cancerous lesions are identified in patients with UC [6]. In this survey, $21 \%$ of patients underwent partial colectomy or endoscopic resection. Detailed information regarding the reason of the decision could not be obtained. The decision was suggested to be made for defecation function preservation. Laparoscopic surgery was performed in $53 \%$ of patients in East Asia. The merit of laparoscopic surgery is a magnified view of the surgical sites, and less traumatic abdominal wall. Overall, laparoscopic surgery and hand-assisted surgery both have a non-inferiority to open proctocolectomy regarding cosmetic results, quality of life, and functional outcome [10-12]. Moreover, the method of anastomosis was surveyed. A meta-analysis comparing hand-sewn versus stapled anastomosis revealed that both had similar outcomes. However, stapled

Questionnaire-Based Survey on

Management of UC-Associated Cancer
Table 3. Characteristics of patient

\begin{tabular}{|c|c|c|}
\hline Characteristics & & $n=125$ \\
\hline Age, years & 52 & $(7-87)$ \\
\hline \multicolumn{3}{|l|}{ Gender } \\
\hline Male & 76 & \\
\hline Female & 49 & \\
\hline \multicolumn{3}{|l|}{ Type of UC } \\
\hline Total colon & 92 & \\
\hline Left colon & 31 & \\
\hline Rectum & 2 & \\
\hline \multicolumn{3}{|l|}{ Medication } \\
\hline 5-ASA & 121 & \\
\hline Steroid & 61 & \\
\hline AZA & 33 & \\
\hline TNFa & 13 & \\
\hline IM & 6 & \\
\hline \multicolumn{3}{|l|}{ Location } \\
\hline Cecum & 5 & \\
\hline Ascending & 12 & \\
\hline Transverse & 8 & \\
\hline Descending & 15 & \\
\hline Sigmoid & 35 & \\
\hline Upper rectum & 30 & \\
\hline Lower rectum & 28 & \\
\hline \multicolumn{3}{|l|}{ Macroscopic type } \\
\hline \multicolumn{3}{|l|}{ Early } \\
\hline Polypoid & 14 & \\
\hline Elevated & 41 & \\
\hline Flat & 18 & \\
\hline Depressed & 7 & \\
\hline \multicolumn{3}{|l|}{ Advanced } \\
\hline Type 1 & 8 & \\
\hline Type 2 & 13 & \\
\hline Type 3 & 11 & \\
\hline Type 4 & 12 & \\
\hline Type 5 & 6 & \\
\hline Size, $\mathrm{mm}$ & 39 & $(5-280)$ \\
\hline \multicolumn{3}{|l|}{ Histology } \\
\hline Tubular & 57 & \\
\hline Poorly & 4 & \\
\hline Signet ring cell & 2 & \\
\hline Mucinous & 5 & \\
\hline \multicolumn{3}{|l|}{ Depth of invasion } \\
\hline$\sim 0$ & 22 & \\
\hline 1 & 15 & \\
\hline 2 & 15 & \\
\hline 3 & 15 & \\
\hline 4 & 10 & \\
\hline \multicolumn{3}{|c|}{ Lymph node metastasis } \\
\hline Absent & 59 & \\
\hline Present & 25 & \\
\hline \multicolumn{3}{|l|}{ Liver metastasis } \\
\hline Absent & 80 & \\
\hline Present & 2 & \\
\hline \multicolumn{3}{|l|}{ Peritoneal metastasis } \\
\hline Absent & 76 & \\
\hline Present & 7 & \\
\hline \multicolumn{3}{|l|}{ Distant metastasis } \\
\hline Absent & 78 & \\
\hline Present & 3 & \\
\hline
\end{tabular}



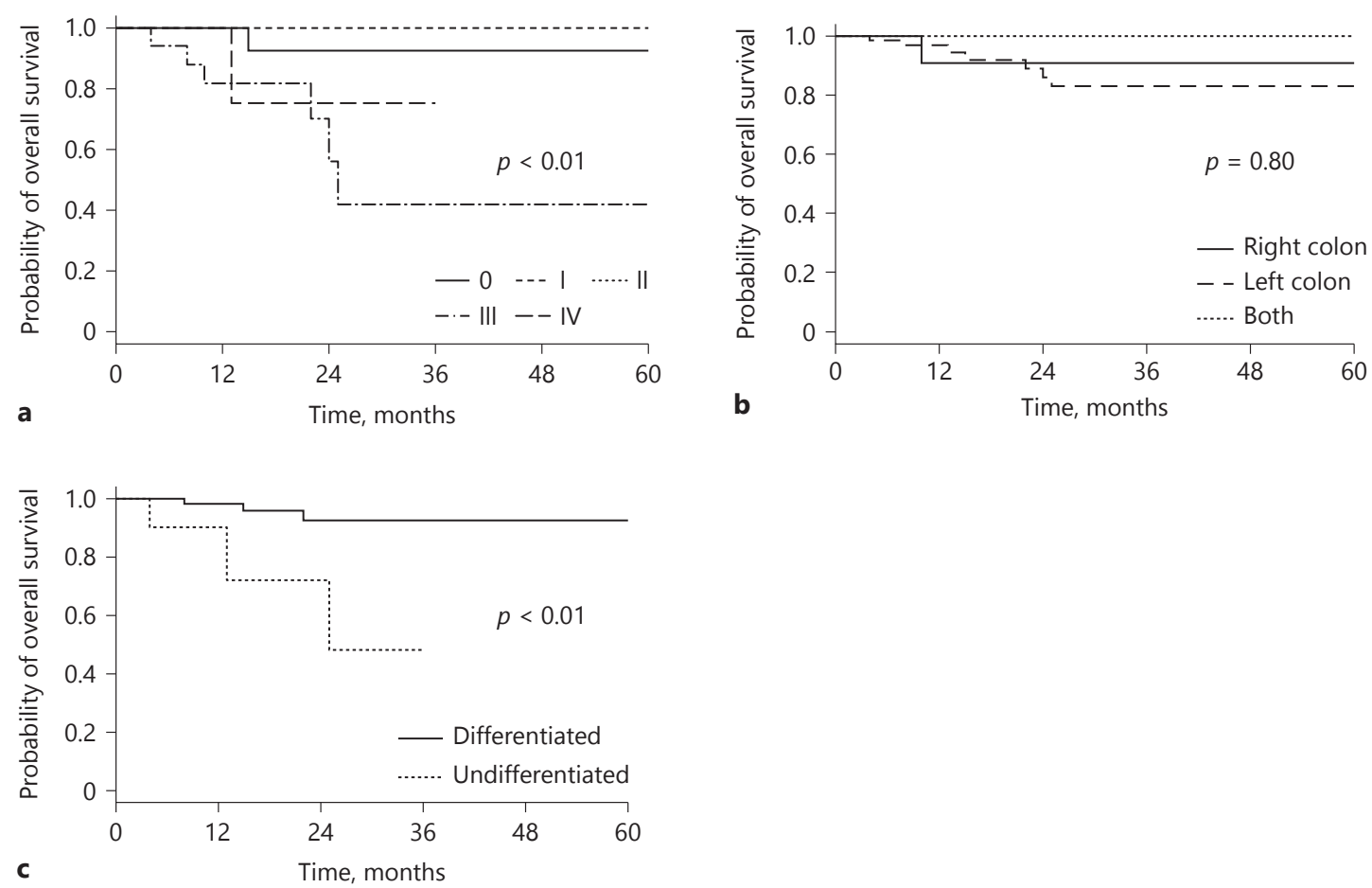

Fig. 6. Survival curves for (a) based on stage, (b) tumor location, and (c) histological types.

Table 4. Treatment of cancer

\begin{tabular}{lc}
\hline Treatment & \\
\hline Endoscopic resection & 1 \\
$\quad$ EMR & 8 \\
$\quad$ ESD & 79 \\
Surgical resection & 10 \\
Chemotherapy & 2 \\
Radiotherapy & $(n=79)$ \\
Surgical cases & 34 \\
Approach & 39 \\
$\quad$ Open & 67 \\
Laparoscopy & \\
Procedure & 9 \\
$\quad$ Total proctocolectomy & 29 \\
Partial colectomy & \\
$\quad$ Hastomosis & 27 \\
$\quad$ Stapler anastomosis &
\end{tabular}

EMR, endoscopic mucosal resection; ESD, endoscopic submucosal dissection. anastomosis improved sleeping, with higher anorectal physiologic testing. A risk of increased incidence of dysplasia in the cuff may exist in stapled anastomosis [13]. The method of anastomosis should be carefully considered because of the risk of bowel function impairment versus the risk of long-term dysplasia caused by ongoing inflammation in the retained rectal mucosa.

Colitis-associated cancer often invades to the deeper layers of the bowel wall from an earlier stage of progression. Poorly differentiated adenocarcinoma and mucinous carcinoma also tend to develop in UC [14]. These undifferentiated tumors show a poorer prognosis in the present study. For these reasons, the relative worse prognosis was accounted particularly in stages II and III cancers. In the present study, the 5-year overall survival was $40 \%$ in stage III. Watanabe et al. [15] reported that the prognosis of sporadic stage III CRC in Japan accounted for 52.9- 83.0\%. A recent report discussed prognostic differences in left and right colon cancers [16]. However, in the present survey, no significant difference was observed regarding the location of the tumor in UC-associated cancer.

The limitation of the present study was the small number of cases, and the majority of the cases were biased to 
some countries. In conclusion, a questionnaire-based survey was conducted to gather current opinions on colitis-associated cancer in different East Asian countries. The current survey elucidated the current management in Asian countries and characteristics of colitis-associated cancer in these countries.

\section{Acknowledgments}

The authors thank all doctors for participating in this survey and the office personnel of the International Gastrointestinal Consensus Symposium for their secretarial work.

\section{Appendix}

Questionnaire: Diagnosis and treatment of ulcerative colitisassociated colorectal cancer in Asia

Your institution ( )

1. Please indicate your country. ( )

2. Are you a specialist in IBD? ( $\square \mathrm{Y} / \square \mathrm{N})$

3. How many UC patient do you treat in your institution in one year? ( ) patients

4. What is your first choice for the treatment of newly diagnosed UC?

$\square 5$-ASAs $\square$ steroid $\square$ AZA $\square$ Anti-TNF $\square$ immunomodulator $\square$ Others (describe:)

5. Cancer surveillance

When do you start the surveillance colonoscopy for UC patients to detect neoplasia?

( ) years from onset

6. Which of the strategies for surveillance colonoscopy do you perform?

$\square$ random biopsies $\square$ targeted biopsies $\square$ other

7. How many colitis cancer patients did you detect/diagnose in last the 5 years?

( ) patients

8. Do you think that color enhancement or narrow band imaging colonoscopy is useful to detect colitis cancer? $(\square \mathrm{Y} / \square \mathrm{N})$
9. Please indicate the proportion of the indication for surgery in your UC patients?

( )\% for neoplasia / ( )\% for severe or refractory colitis

If you have experienced ulcerative colitis-associated colorectal cancer case in past 5 years, please describe the next questionnaire in each patient.

Your country ( ) Your institution ( )

Arbitrary case number ( )

1. Age ( ) years old

2. Gender $\square$ Male $\square$ Female

3. Years from onset of UC ( ) years

4. Type of UC $\square$ total colon $\square$ left colon $\square$ rectum

5. What kind of treatment did you administer in this patient?

$\square 5$-ASAs $\square$ steroid $\square$ AZA $\square$ Anti-TNF $\square$ immuno-modulator $\square$ Others (describe:)

6. Location of neoplasia $\square$ Cecum $\square$ Ascending $\square$ Transverse $\square$ Descending $\square$ Sigmoid $\square$ Upper Rectum $\square$ Lower Rectum

7. How many times did you do surveillance colonoscopy to detect this neoplasia? ( ) times

8. Macroscopic types (early cancer) $\square$ polypoid $\square$ elevated $\square$ flat $\square$ depressed

9. Macroscopic types (advanced cancer) $\square$ Borrmann1 $\square 2 \square 3$ $\square 4 \square 5$

10. Tumor size ( ) $\mathrm{mm}$

11. Histological types ( )

12. Depth of tumor invasion ( )

13. Metastatic lesions

Lymph node metastasis (Regional lymph nodes) $\square$ positive $\square$ negative

Liver metastasis (H) $\square$ positive $\square$ negative

Peritoneal metastasis (P) $\square$ positive $\square$ negative

Extrahepatic distant metastasis (M) $\square$ positive $\square$ negative

14. According to UICC TNM classification $\mathrm{T}(\quad) \mathrm{N}(\quad) \mathrm{M}(\quad)$

15. Treatment $\square$ Endoscopic treatment ( $\square$ EMR $\square$ ESD) $\square$ Sur-

gical treatment $\square$ Chemotherapy $\square$ Radiotherapy

If available, please describe below

Approach to the lesion $\square$ open $\square$ laparoscopic

Surgical procedures $\square$ total colectomy $\square$ partial colectomy

Anastomosis $\square$ Hand-sewn $\square$ stapler

16. Adjuvant therapy $\square$ Non $\square$ Chemotherapy $\square$ Radiotherapy

17. Prognosis $\square$ Alive ( ) months from intervention $\square$ Dead ( ) months from intervention.

\section{References}

1 Eaden JA, Abrams KR, Mayberry JF: The risk of colorectal cancer in ulcerative colitis: a meta-analysis. Gut 2001;48:526-535.

2 Jess T, Rungoe C, Peyrin-Biroulet L: Risk of colorectal cancer in patients with ulcerative colitis: a meta-analysis of population-based cohort studies. Clin Gastroenterol Hepatol 2012;10:639-645.

3 Hata K, Watanabe T, Kazama S, Suzuki K, Shinozaki M, Yokoyama T, Matsuda K, Muto T, Nagawa H: Earlier surveillance colonoscopy programme improves survival in patients with ulcerative colitis associated colorectal cancer: results of a 23 -year surveillance pro- gramme in the japanese population. Br J Cancer 2003;89:1232-1236.

4 Chang DK, Kim YH, Byeon JS, Yang SK, Chung YW, Han DS, Kim SG, Kim TI, Kim WH, Jeen YT, Eun CS, Choi H, Choi KY, Song IS; KASID: [The current status of ulcerative colitis-associated colorectal cancer in korea: a KASID study]. Korean J Gastroenterol 2005;46:276-282.

5 Rogler G: Chronic ulcerative colitis and color ectal cancer. Cancer Lett 2014;345:235-241.

6 Tanaka T, Kobunai T, Yamamoto Y, Emoto S, Murono K, Kaneko M, Sasaki K, Otani K, Nishikawa T, Kawai K, Hata K, Nozawa $H$, Watanabe T: Colitic cancer develops through mutational alteration distinct from that in sporadic colorectal cancer: a comparative analysis of mutational rates at each step. Cancer Genomics Proteomics 2017;14:341-348.

7 Beintaris I, Rutter M: Advanced imaging in colonoscopy: contemporary approach to dysplasia surveillance in inflammatory bowel disease. Frontline Gastroenterol 2016;7:308-315.

8 Laine L, Kaltenbach T, Barkun A, McQuaid KR, Subramanian V, Soetikno R SCENIC international consensus statement on surveillance and management of dysplasia in inflammatory bowel disease. Gastrointest Endosc 2015;81:489-501.e26.
Questionnaire-Based Survey on

Management of UC-Associated Cancer 
9 Yang DH: [Recent advances in understanding colorectal cancer and dysplasia related to ulcerative colitis]. Korean J Gastroenterol 2015; 66:312-319.

10 Polle SW, Dunker MS, Slors JF, Sprangers MA, Cuesta MA, Gouma DJ, Bemelman WA: Body image, cosmesis, quality of life, and functional outcome of hand-assisted laparoscopic versus open restorative proctocolectomy: long-term results of a randomized trial. Surg Endosc 2007;21:1301-1307.

11 Polle SW, van Berge Henegouwen MI, Slors JF, Cuesta MA, Gouma DJ, Bemelman WA: Total laparoscopic restorative proctocolectomy: are there advantages compared with the open and hand-assisted approaches? Dis Colon Rectum 2008;51:541-548.
12 Baek SJ, Lightner AL, Boostrom SY, Mathis KL, Cima RR, Pemberton JH, Larson DW, Dozois EJ: Functional outcomes following laparoscopic ileal pouch-anal anastomosis in patients with chronic ulcerative colitis: longterm follow-up of a case-matched study. J Gastrointest Surg 2017;21:1304-1308.

13 Lovegrove RE, Constantinides VA, Heriot AG, Athanasiou T, Darzi A, Remzi FH, Nicholls RJ, Fazio VW, Tekkis PP: A comparison of hand-sewn versus stapled ileal pouch anal anastomosis (IPAA) following proctocolectomy: a meta-analysis of 4183 patients. Ann Surg 2006;244:18-26.

14 Connell WR, Talbot IC, Harpaz N, Britto N, Wilkinson KH, Kamm MA, Lennard-Jones JE: Clinicopathological characteristics of colorectal carcinoma complicating ulcerative colitis. Gut 1994;35:1419-1423.
15 Watanabe T, Itabashi M, Shimada $Y$, Tanaka S Ito Y, Ajioka Y, Hamaguchi T, Hyodo I, Igarashi $M$, Ishida $H$, Ishihara $S$, Ishiguro $M$, Kanemitsu Y, Kokudo N, Muro K, Ochiai A, Oguchi M, Ohkura Y, Saito Y, Sakai Y, Ueno H, Yoshino T, Boku N, Fujimori T, Koinuma N, Morita T, Nishimura G, Sakata Y, Takahashi K, Tsuruta O, Yamaguchi T, Yoshida M, Yamaguchi N, Kotake K, Sugihara K; Japanese Society for Cancer of the Colon and Rectum: Japanese society for cancer of the colon and rectum guidelines 2014 for treatment of colorectal cancer. Int J Clin Oncol 2015;20:207-239.

16 Wang B, Yang J, Li S, Lv M, Chen Z, Li E, Yi $M$, Yang J: Tumor location as a novel high risk parameter for stage II colorectal cancers. PLoS One 2017;12:e0179910. 